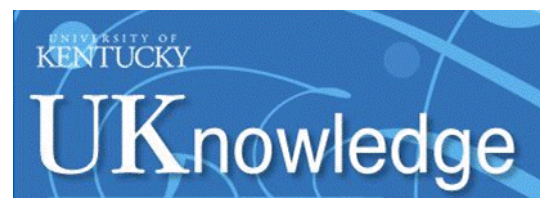

University of Kentucky

UKnowledge

$10-2018$

\title{
Can Maternity Benefits Have Long-Term Effects on Childbearing? Evidence from Soviet Russia
}

Olga Malkova

University of Kentucky, o.malkova@uky.edu

Follow this and additional works at: https://uknowledge.uky.edu/economics_facpub

Part of the Benefits and Compensation Commons, Economics Commons, Soviet and Post-Soviet Studies Commons, and the Statistics and Probability Commons

Right click to open a feedback form in a new tab to let us know how this document benefits you.

\section{Repository Citation}

Malkova, Olga, "Can Maternity Benefits Have Long-Term Effects on Childbearing? Evidence from Soviet Russia" (2018). Economics Faculty Publications. 4.

https://uknowledge.uky.edu/economics_facpub/4

This Article is brought to you for free and open access by the Economics at UKnowledge. It has been accepted for inclusion in Economics Faculty Publications by an authorized administrator of UKnowledge. For more information, please contact UKnowledge@lsv.uky.edu. 


\section{Can Maternity Benefits Have Long-Term Effects on Childbearing? Evidence from Soviet Russia}

\section{Digital Object Identifier (DOI)}

https://doi.org/10.1162/rest_a_00713

Notes/Citation Information

Published in The Review of Economics and Statistics, v. 100, issue 4, p. 691-703.

(C) 2018 by the President and Fellows of Harvard College and the Massachusetts Institute of Technology The copyright holder has granted the permission for posting the article here. 


\title{
CAN MATERNITY BENEFITS HAVE LONG-TERM EFFECTS ON CHILDBEARING? EVIDENCE FROM SOVIET RUSSIA
}

\author{
Olga Malkova*
}

\begin{abstract}
This paper quantifies the effects of Russia's 1981 expansion in maternity benefits on completed childbearing. The program provided one year of partially paid parental leave and a small cash transfer upon a child's birth. I exploit the program's two-stage implementation and find evidence that women had more children as a result of the program. Fertility rates rose immediately by $8.2 \%$ over twelve months. The increase in fertility rates not only persisted for the ten-year duration of the program, but it reflected large increases in higher-order births to older women who already had children before the program started.
\end{abstract}

\section{Introduction}

$\mathrm{E}$ IGHTY-FOUR percent of developed countries offer subsidies or parental leave benefits at an average cost of 2.6\% of GDP (United Nations, 2013). Some of these programs are tremendously expensive. Countries implement these programs in part to increase childbearing, because they are worried that below-replacement-fertility levels accompanied by an increase in life expectancy may negatively affect their economies in several ways. ${ }^{1}$ First, this demographic shift threatens the ability of many countries to finance old-age benefits. Second, a shrinking working-age population compared to a rising elderly population may result in lower economic growth because of a decline in workers per capita (Bloom et al., 2010). Although maternity benefits are costly, they may be ineffective if they result in only a short-run increase in childbearing due to a shift in timing of childbearing instead of a long-run increase due to women having more children.

Whether these programs are effective in raising childbearing is an open question. The provision of more generous parental benefits is associated with a country's demand for children, which makes estimating the effects of programs themselves difficult. To address this problem, the literature uses a variety of natural experiments in different

Received for publication September 2, 2016. Revision accepted for publication July 24, 2017. Editor: Amitabh Chandra.

* University of Kentucky.

I thank Martha Bailey, Hoyt Bleakley, Charles Brown, John DiNardo, David Lam, Jeffrey Smith, Ugo Troiano, and Robert Willis for helpful discussions. Comments from seminar participants at Clemson University, Indiana University, Purdue University, Syracuse University, UC Davis, University of Kentucky, the University of Michigan, and conference participants at SOLE, the International Institute of Public Finance (IIPF), the ZEW, the Midwest Economic Association, the CAFÉ workshop hosted by Aarhus University, the Southern Economic Association, and Population Association of America helped to improve the paper. I thank the ZEW for recognizing this paper with the Heinz Konig Young Scholar Award, the IIPF for the Young Economists Award, and Population Association of America for the Dorothy Thomas Award.

A supplemental appendix is available online at http://www.mitpress journals.org/doi/suppl/10.1162/rest_a_00713.

${ }^{1}$ The total fertility rate is below replacement in 113 countries (Central Intelligence Agency, 2013). Population aging is a concern for $92 \%$ of developed countries (United Nations, 2013). countries to provide evidence that parental leave (Lalive \& Zweimüller, 2009, for Austria) and cash transfer programs (Cohen, Dehejia, \& Romanov, 2013, for Israel; Gonzalez, 2013, for Spain; Milligan, 2005, for Canada) have shortrun, positive effects on childbearing in developed countries. But the limited time horizon of available data and empirical methods limits inferences about long-run effects. Consequently, many of the estimated effects may reflect changes in the timing rather than a permanent increase in childbearing.

This paper leverages the two-stage introduction of Russia's 1981 expansion of maternity benefits to evaluate both its short-run and long-run effects on childbearing. Similar to the goals of programs in developed countries today, the program was intended to increase completed childbearing by providing a sizable expansion in partially paid parental leave until a child turned 1 year old, unpaid parental leave until a child turned 18 months, and small cash transfers at the birth of the first, second, or third child. Eighty-five percent of women were eligible for benefits because they met the provision stipulating that they be in the labor force.

My research design uses the Soviet government mandate that the benefits start in 1981 in 32 oblasts (similar to states; I call these oblasts "early beneficiaries"), and then in 50 oblasts ("late beneficiaries") one year later. The historical vantage point allows me to estimate long-run effects of the maternity benefits expansion. Another contribution of the project is the reconstruction of Russian population and characteristics of regional data from recovered vital statistics, censuses, yearbooks, and surveys, which I cull and translate from published sources.

My results show that the 1981 Russian maternity benefit program is associated with an immediate and sustained increase in childbearing. Fertility rates rose immediately after the program started by approximately $8.2 \%$ in the first twelve months. The elasticity of fertility rates with respect to a change in cost of a child (for the first 18 years) is -3.7 , which is in the range of short-run effects found in other studies. $^{2}$ Three empirical findings underscore that this increase reflects higher completed childbearing. First, period fertility rates remained on average $14.6 \%$ higher for the ten-year duration of the program. Second, children born after the expansion were more likely to have been higher-order births. Third, these higher-parity children were born to mothers who were older and had a longer interval since her previous birth.

\footnotetext{
${ }^{2}$ Using prior literature estimates, I calculate elasticities: -4.4 in Austria, -3.8 in Spain, and -4.1 in Canada, while -0.54 is already reported in Israel.
} 
This study is the first to find a positive effect of maternity benefits on long-run fertility rates. ${ }^{3}$ This is at odds with some papers that have argued that maternity benefits have small or no effects on raising short-run fertility rates and long-run childbearing (Demeny, 1986; Gauthier \& Hatzius, 1997). ${ }^{4}$ Theoretically, maternity benefits could decrease childbearing over the longer term. To demonstrate this, I develop two theoretical extensions of the Becker and Lewis (1973) model that incorporate two types of maternity benefits: paid leave, which lowers the opportunity cost of childbearing, and a cash transfer, which increases income. The first extension allows parents to choose both the number of children and their level of investments in each child ("quality"), which has the well-known effect of making the income effect theoretically ambiguous. The second extension achieves the same result through nonstandard channels: by allowing women to make endogenous choices about their time off from work.

Theoretically, the effect of maternity benefits on childbearing depends on the shadow price of a child and on income (Becker, 1965; Galor \& Weil, 1999). Less educated and more rural areas experienced a greater increase in fertility rates for the duration of the program. Maternity benefits may have had long-run effects on childbearing in Russia because Russian women had both low opportunity costs and low costs of raising children. My best evidence on this comes from the fact that Russian women had lower earnings compared to men and a flatter age-earnings profile than women in other countries (Brainerd, 2000; Gregory \& Kohlhase, 1988). They also had access to widespread and affordable preschool care for children of all ages.

Although my findings suggest that disadvantaged mothers increased their childbearing the most, I find no effect of maternity benefits on outcomes of children in adulthood. This effect reflects both the direct effect due to the change in the time spent with children and in household income, as well as the indirect effect due to the change in the composition of mothers. Children born one year after maternity benefits started had similar educational, economic, and family structure outcomes compared to the children born right before.

In summary, this paper shows that maternity benefits can have an effect on both short-run and long-run childbearing behavior. In the Russian case, the program induced nearly 5 million births over its duration, where an extra birth cost the government about 1.4 times a year's average national earnings. However, behavioral responses to maternity bene-

\footnotetext{
${ }^{3}$ Lalive and Zweimüller (2009) find that women who randomly received extra paid leave for the first child were more likely to have a second child. However, their result may be due to additional eligibility for automatic renewal of benefits if a second birth happened up to 27.5 months after the first birth and is not applicable to typical interventions affecting benefits for future births.

${ }^{4}$ Papers on the United States focus on low-income women and find inconclusive evidence on effects of welfare policies on childbearing (Hoynes, 1997; Moffitt, 1998).
}

fits may vary across contexts and will reflect the interaction of maternity benefits with other social programs.

\section{Russian Family Benefits}

Before 1981, the major beneficiaries of family subsidies were families with many children or low-income families. From 1947, women received a one-time payment beginning with their third child and monthly supplements until a child's fifth birthday beginning with their fourth child (Presidium Verhovnogo Soveta, 1947). ${ }^{5}$ In addition, after 1974, families with per capita income below a threshold received monthly supplements for each child under the age of eight (Presidium Verhovnogo Soveta, 1974). However, many families were not eligible for these benefits.

The government also provided benefits to working mothers but did not provide financial support for women who wanted to stay home with a child for a longer period of time. The most generous benefit was a fully paid maternity leave of 56 days before and 56 days after a birth. In addition, women could take an unpaid job-protected parental leave until a child turned 1 year old (Goskomtrud, 1970). Job-protected leave was an important feature in Soviet Russia, where about half of the labor force consisted of women in 1980.

In the late 1970s, the Soviet government formulated a pronatalist policy with the goal of encouraging all women to have second and third births. The government was interested in securing the replacement level of children "from each physically and morally healthy family, instead of a maximum of children from a minimum of families" (Desfosses, 1981). One of the motivations was the desire to achieve greater population growth in areas with labor shortages (DiMaio, 1981). ${ }^{6}$ In January 1978, Litvinova (1978), the senior research associate with the Institute of State and Law of the USSR Academy of Sciences, wrote that "the state cannot be indifferent to what kind of population increase occurs, whether it is highly mobile or, owing to a variety of circumstances (including large families and language barriers), bound to one specific region."

\section{A. Description of the Maternity Benefits Expansion}

The outcome of these discussions was the 1981 maternity benefit program that aimed to increase childbearing by providing "good conditions for population growth," to "ease the status of working mothers," and to "decrease the differences in standard of living depending on having children" (TSK KPSS, 1981). This program provided three new benefits.

\footnotetext{
${ }^{5}$ All full citations to Soviet laws and newspaper articles are listed in online appendix A. Laws have citations that start with "Goskomtrud," "Presidium," and "TSK KPSS." I also cite two major newspapers: Pravda and Izvestija.

${ }^{6}$ Women in the Central Asia republics were the majority of beneficiaries of income-tested and higher-parity birth benefits. Mobility from these republics was low. Thus, the government sought to provide incentives for childbearing in regions with lower populations and labor shortages.
} 
First, women received partially paid parental leave until a child turned 1 year old, which was a flat monthly payment equaling $27 \%$ of the average national female monthly salary. ${ }^{7}$ Paid parental leave was the most substantial part of the program and was the same for all parities. Second, women could keep their job while staying home until their child turned 18 months old. Third, women received a small one-time cash transfer: $38 \%$ and $76 \%$ of the average national monthly salary for first and second or third births, respectively. ${ }^{8}$ Although this one-time transfer was $100 \%$ more for the second and third birth, the sum of partially paid leave and the transfer for second and third births was only $9 \%$ more than the sum for first births, once partially paid leave is included.

Unlike previous programs for poor or large families, most families were eligible for benefits. Women who worked for at least a year as well as students regardless of work experience were eligible. ${ }^{9}$ Nonworking women were also eligible for a small one-time flat transfer for first, second, and third births, equaling about $20 \%$ of the average national female monthly wage. Given that $85 \%$ of women were employed and $59 \%$ of college students were women, this program covered the vast majority of women. Notably, the program left previous means-tested benefits and benefits for large families unchanged. ${ }^{10}$

Although the benefits lasted about ten years, women likely expected them to stay in place permanently. The government had never canceled previous benefits and typically expanded them. In fact, in 1989, partially paid and unpaid leaves were expanded to 18 months and 3 years after birth, respectively (Sovmin, 1989). However, by 1992, hyperinflation reduced the benefit to almost 0 , and the subsequent collapse of the Soviet Union ended the program.

\section{Expected Effects of Russian Maternity Benefits on Childbearing}

Introducing paid parental leave and birth transfers directly reduced the cost of having a child for working women. In the neoclassical consumer model, parents maximize utility, $U(n, z)$, choosing the quantity of children, $n$, and another consumption good, $z$. Parents face a simple lifetime budget constraint, $\left[t\left(w_{f}-a\right)-b\right] n+\pi_{z} z=T\left(w_{f}+\right.$ $w_{m}$ ), where both the husband and wife can work for units of time, $T$, while the wife receives $w_{f}$ for her work and the husband receives $w_{m}$ for his work. I assume that only women take time off, $t$, to take care of each child, for which they receive a benefit, $a$, thus making the benefit-adjusted oppor-

\footnotetext{
${ }^{7}$ Women received ten payments (fully paid leave covered the first two months after birth): 50 rubles per month in Siberia, the Far East, and the Northern regions and 35 rubles in the rest of Russia. However, benefits represented the same share of the average regional monthly salary $(27 \%)$.

${ }^{8}$ The one-time transfer was 50 and 100 rubles for the first and second/ third child, respectively.

${ }^{9}$ Students from universities, professional, technical, and clinical schools were eligible.

${ }^{10}$ Only the one-time transfer for a third birth increased from 20 to 100 rubles.
}

tunity cost of child rearing, $t\left(w_{f}-a\right) .{ }^{11}$ Finally, women receive a cash transfer, $b$, for each child, and spend $\pi_{z}$ on each unit of consumption good, $z$.

This model predicts that both an increase in paid leave, $a$, and cash transfers, $b$, will increase the number of children, as long as children are normal goods. ${ }^{12}$ However, the number of children need not increase when the cost of children decreases, even if children are normal goods, once the model also allows parents to choose quality or choose mothers' time off from work.

\section{A. Maternity Benefits with Endogenous Choice of Child Quantity and Quality}

Maternity benefits may lead women to have fewer children due to the interaction of quantity and quality. It may become optimal for women to have fewer children if they invest more in each child because of the benefits, producing children of a higher quality. To demonstrate this, I incorporate the choice of child quality, $q$, in the neoclassical consumer model. Parents maximize utility, $U(n, q, z)$ and face a lifetime budget constraint, $\pi q n+\left[t\left(w_{f}-a\right)-b\right] n+\pi_{z} z=T\left(w_{f}+w_{m}\right)$, paying, $\pi$, for a quality unit of a child, which they must spend on each child individually, such as college tuition. This budget constraint differs from the one in the standard quantity-quality model (Becker \& Lewis, 1973; Willis, 1973), because it incorporates maternity benefits into the cost of a child. Using this framework, appendix $\mathrm{C}$ shows that the elasticity of childbearing with respect to parental leave can be expressed as the weighted sum of the income $\left(\epsilon_{i}\right)$ and substitution $\left(\epsilon_{s}\right)$ elasticities, $\operatorname{dln}(n) / \operatorname{dln}(a)=(a t n / I) \epsilon_{i}+\epsilon_{s}$. Proposition 1 and corollary 1 show that even if children are normal goods, the observed effect of an increase in income through the introduction of paid leave and a cash transfer on childbearing may be negative.

Proposition 1. The effect of parental leave, a, on childbearing, $n$, is positive if the difference of the true income elasticity for quantity and the true income elasticity for quality, $\eta_{n}-\eta_{q}$, is sufficiently large enough (condition for the income elasticity to be positive). ${ }^{13}$

Proof. See appendix C. Also see appendix C for corollary 1 , which focuses on the elasticity with respect to the cash transfer, $b$, and its proof.

\section{B. Maternity Benefits with Endogenous Choice of Time Off}

Another way maternity benefits may lead women to have fewer children is through the interaction of quantity and time

\footnotetext{
11 This model does not limit the length of paid leave, $t$, but it is less than one year in this context.

12 This reflects that the effect of maternity benefits, $d n / d a$ and $d n / d b$, is the sum of income and substitution effects, which are both positive. A growing empirical literature suggests that husband's earnings (Lindo, 2010; Black et al., 2013) and housing wealth (Lovenheim \& Mumford, 2013) have positive effects on completed childbearing.

${ }^{13} \eta_{n}$ and $\eta_{q}$ use a measure of income calculated using shadow prices (marginal costs) whose ratios in equilibrium are equal to the marginal rates of substitution in the utility function.
} 
off from work. To see this, I extend the neoclassical consumer model by incorporating the choice of time off from work, $t$, for the mother. Households maximize utility, $U(n, t, z)$, and face a lifetime budget constraint, $\left[t\left(w_{f}-a\right)-b\right] n+\pi_{z} z=$ $T\left(w_{f}+w_{m}\right)$. Unlike in the quantity-quality extension, the household's problem no longer involves quality, but the mother may now choose time off from work, $t$, while paying wages less the parental leave benefit, $w_{f}-a$, for each time unit spent out of the labor force for each child.

A notable feature of parental leave benefits is that they subsidize not only the quantity but also potentially the quality of children because they reduce the opportunity cost of the mother's time with her child. ${ }^{14}$ This feature renders the interpretation of time off from work, $t$, as similar to that of quality, $q$, in the previous extension. If women spend more time out of the labor force when they have access to partially paid leave, it may result in a greater cost of a child in a world with paid leave compared to the world with unpaid leave. Using this framework, appendix C shows that the elasticity of childbearing with respect to parental leave can be expressed in the same form as when child quality was endogenous. Proposition 2 and corollary 2 show that even if children are normal goods, the effect of paid leave and a cash transfer on childbearing may be negative.

Proposition 2. The effect of parental leave, a, on childbearing is positive if the difference of the true income elasticity of quantity and the true income elasticity of time off, $\eta_{n}-\eta_{t}$, is sufficiently large enough (condition for the income elasticity to be positive) and the partial elasticity of substitution between $n$ and $t, \sigma_{n}$, is positive (condition for the substitution elasticity to be positive).

Proof. See appendix C. Also see appendix C for corollary 2 , which focuses on the elasticity with respect to the cash transfer, $b$, and its proof.

The extension of job protection from 1 year to 18 months may increase or decrease completed childbearing. This extension lowers the labor market costs of a birth and allows women to have another child up to 20 months after birth (14 months before the policy was extended), while keeping their job and becoming eligible for new maternity benefits. ${ }^{15}$ This may result in an increase in completed childbearing and in women having subsequent births sooner. However, taking more unpaid leave may lead women to have fewer children because the increase in their forgone earnings may result in a greater cost of a child. ${ }^{16}$

\footnotetext{
${ }^{14}$ Mother's time with a child may improve child quality if preschool or the care of relatives are not perfect substitutes. In this context, subsidized preschool was available since the age of 2 months.

${ }^{15}$ A woman became eligible for fully paid maternity benefits two months before a birth.

${ }^{16}$ The intuition is similar to the one in proposition 2, but now the time off from work is unpaid.
}

Table 1.-Characteristics of Early and Late Beneficiary Oblasts

\begin{tabular}{lcc}
\hline \hline Type of Beneficiary & Early & Late \\
\hline Proportion of population in 1979 & & \\
With college degree among employed & $9.0 \%$ & $9.1 \%$ \\
With less than high school among employed & $46.3 \%$ & $48.6 \%$ \\
Employed among women ages 15 to 54 & $84.1 \%$ & $85.5 \%$ \\
In rural areas among women ages 15 to 44 & $25.7 \%$ & $24.9 \%$ \\
In preschool among children younger than 7 & $52.5 \%$ & $51.9 \%$ \\
Ages 15 to 44 among women & $46.6 \%$ & $42.0 \%$ \\
Ages 65 years and older among women & $9.6 \%$ & $14.7 \%$ \\
General fertility rate in 1980 & 75.9 & 67.1 \\
Higher parity fertility rate in 1980 & 37.4 & 31.6 \\
Number of oblasts & 37 & 51 \\
Share population living in oblasts & $26.5 \%$ & $73.5 \%$ \\
\hline Sources: 1979 Soviet Census; 1979 Narodnoe Hozyaystvo yearbook; Rosstat; 2010 Russian Census.
\end{tabular}

\section{Rollout of Russian Maternity Benefits}

On January 22, 1981, the Soviet government passed a ruling about its intention to expand maternity benefits (TSK KPSS, 1981). The ruling described the components of the program, the exact benefit amounts, and eligibility requirements. ${ }^{17}$ The ruling stated that the program was to be implemented in waves around the country. The early beneficiaries of the program were the Far East, Siberia, and the Northern regions, while the late beneficiaries were the rest of the Russian regions. The announcement stated that the early beneficiaries would start receiving benefits in 1981, but did not provide any information on when benefits would start in late beneficiaries.

The Russian government may have decided the order of the benefits because it prioritized population growth in areas with labor shortages that were important in terms of industrial production (Weber \& Goodman, 1981). Perevedentsev (1974), a highly respected population economist, wrote, "The task for the next 10 years is to balance the distribution of the country's population and natural resources. It is the East that has the most abundant natural resources." 18 The early beneficiaries were less populous and only $26.5 \%$ of the Russian population resided there. Figure B1 shows a map of the rollout of benefits across Russia. Table 1 shows that the share of employed women, educated individuals, women living in rural areas, and children in preschool were similar in early and late beneficiaries in 1980 . However, the population in early beneficiaries was, on average, younger relative to the late beneficiaries, which may explain higher fertility rates in early beneficiaries.

Women were aware of the details of the maternity benefit program even before the ruling because the introduction of this program was widely publicized in major Russian newspapers. The first mention of the program was on December 2, 1980, in both major Russian newspapers Pravda, 1980,

\footnotetext{
${ }^{17}$ The ruling also mentioned plans for expanding other services such as kindergartens and housing (Sovmin, 1981a). However, these plans were vague, they were for the next ten-year period, not to be implemented in stages, and not mentioned in future rulings (Presidium Verhovnogo Soveta, 1981; Sovmin, 1981b). Thus, I measure the effect of maternity benefits not inclusive of these plans; year fixed effects account for any other changes happening at the national level.

${ }^{18}$ Chinn (1977) wrote that "Siberia and the Far East should grow relative to the rest of the country."
} 
and Izvestija, 1980). Several other articles discussed these plans in more detail before and after the official announcement in January and mentioned that they would be introduced in waves starting in 1981 (Pravda, 1981a; Izvestija, 1981a). ${ }^{19}$ The newspapers also mentioned receiving a lot of mail with positive reviews of the program, and one woman wrote that people in every house in her town were talking about the new program (Pravda, 1981b; Izvestija, 1981b).

Later, on September 2, 1981, a government ruling announced the exact timing of the start of benefits across regions (Presidium Verhovnogo Soveta, 1981; Sovmin, 1981b), and it appeared in a major newspaper shortly afterward (Izvestija, 1981d). This time it stated that the early beneficiaries would receive benefits starting on November 1,1981 . The late beneficiaries would receive benefits starting on November 1, 1982. Women who gave birth after implementation could receive the monthly paid leave for the remaining months after implementation until the child turned 1 year old, but could not receive the one-time birth transfer (Goskomtrud, 1982). The timing of benefit eligibility depended on the location of permanent work or study and not on the place of birth of the child or residence. ${ }^{20}$

\section{Effect of Maternity Benefits on Childbearing in the Short Run}

I analyze whether maternity benefits affected childbearing in the short run by quantifying their effect within a year of their start. To do this, I construct the general fertility rate (GFR) - the annual number of births per thousand women ages 15 to 44 . I use nonpublic data on the annual number of births by oblast from the Russian Federal State Statistics Service (Rosstat). ${ }^{21}$ For the denominator, I use the 1989 Russian census to estimate the number of women ages 15 to 44 in each year and oblast. The details for fertility rate estimation are in appendix D.

\section{A. Descriptive Evidence on Childbearing Responses to Maternity Benefits}

The evolution of fertility rates in early and late beneficiary oblasts provides preliminary evidence of a positive effect of the maternity benefit program on childbearing. Figure 1 shows that early and late beneficiaries had similar trends in fertility rates before the program. The GFR in the early beneficiaries jumped in 1981 and rose further in 1982, when benefits were in place for a full year. The GFR in the

\footnotetext{
19 The most detailed description of the law appears on March 31, 1981, as front-page news in both major Russian newspapers (Izvestija, 1981c; Pravda, 1981c).

${ }^{20}$ Housing shortages and the internal passport system limited geographic mobility (Brainerd, 1998).

${ }^{21}$ These data are reliable to estimate the effect of maternity benefits on childbearing. I have estimated this effect on GFR constructed using several data sources. All estimates were positive, similar in magnitude, and statistically different from 0 . The data sources were the nonpublic data from Rosstat, 1989 Census data, 2002 Census data, and 2010 Census data.
}

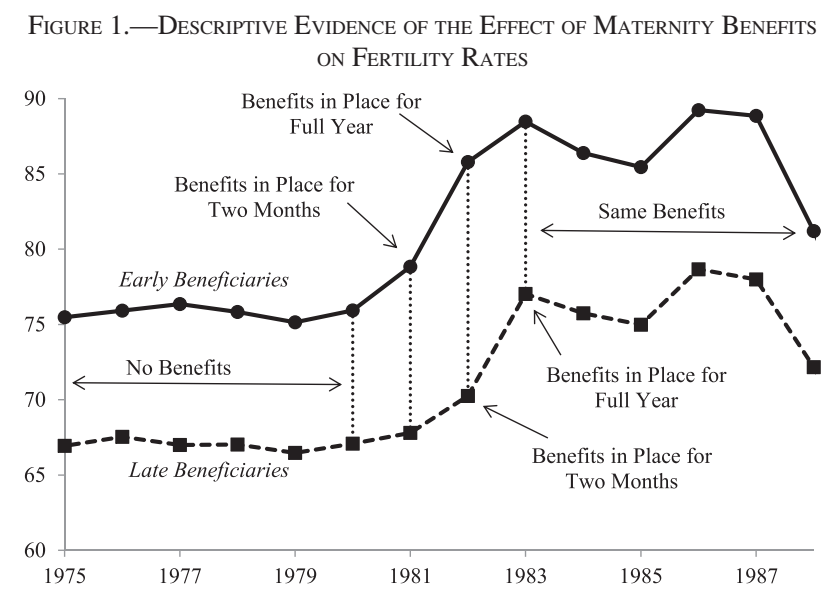

The figure plots the evolution of general fertility rates (GFR) in the early and late beneficiary regions The GFR is the number of births per thousand women ages 15 to 44

Sources: Russian Federal State Statistics Service (Rosstat) and the 1989 Russian Census.

late beneficiaries did not decrease in 1981, suggesting women did not delay childbearing after the benefit announcement. Similar to behavior in early beneficiaries, GFR in late beneficiaries jumped in 1982 and rose further in 1983 when benefits were in place for a full year. Finally, fertility rates in both early and late beneficiaries stayed higher after the program, suggesting an increase in completed childbearing.

\section{B. Generalized Differences-in-Differences Framework}

I next use this two-stage implementation in a generalized differences-in-differences framework to adjust these raw comparisons for other covariates (Jacobson, LaLonde, \& Sullivan, 1993),

$$
\begin{aligned}
G F R_{o, y}= & \alpha+\gamma_{y}+\delta_{o}+\sum_{t=1975}^{1979} \theta_{t} \times D_{o} \times 1(y=t) \\
& +\sum_{t=1981}^{1986} \pi_{t} \times D_{o} \times 1(y=t)+X_{o, y}+\varepsilon_{o, y},
\end{aligned}
$$

where $G F R_{o, y}$ is the general fertility rate in oblast $o$ and year $y, \gamma$ is a set of year fixed effects that capture changes common to all oblasts, $D_{o}$ equals 1 if an oblast was an early beneficiary, and $\delta$ is a set of oblast fixed effects that capture time-invariant oblast level differences. The dummy for the year before the start of the program, $1(y=1980)$, is omitted, which normalizes the estimates for $\theta$ and $\pi$ to 0 in $1980 .^{22}$ The regression also includes covariates that vary at the year and oblast level and measure output and economic activity: amount of bricks, concrete, timber, meat, and canned goods produced and the value of retail trade. ${ }^{23}$

\footnotetext{
${ }^{22} \theta$ and $\pi$ are vectors that contain coefficients, $\theta_{t}$ and $\pi_{t}$, for years $t$ 1975-1979 and 1981-1986.

${ }^{23}$ These covariates represent the most relevant statistics available for that time period at the oblast and year level, which I manually entered using Narodnoe Hozyaystvo (National Economy) yearbooks.
} 
These covariates test whether the change in fertility rates was due to other coincidental economic shocks across regions.

The coefficient $\pi_{1981}$ captures the effect of the program on fertility rates in early beneficiaries in the first two months; $\pi_{1982}$ captures this effect in the first full year. These coefficients may be biased upward if women in late beneficiaries delayed childbearing in response to the benefit announcement. I find no evidence of this; fertility rates in late beneficiaries experienced an insignificant $0.63 \%$ increase between November 1981 and October 1982. ${ }^{24}$ The coefficients $\pi_{1983}$ to $\pi_{1986}$ capture the reversion of the mean difference to its preprogram level after the late beneficiaries gained eligibility. If the late beneficiaries increased their fertility rates once they became eligible for the full year of benefits, $\pi_{1983}$ to $\pi_{1986}$ should be smaller in magnitude compared to $\pi_{1982}$, when the two areas differed in eligibility. The point estimates, $\theta$, test whether fertility rates were on parallel trends before the start of the benefits.

Similarly, I estimate the effect of the replacement rate (maternity benefits transfers relative to average wages in a region) on childbearing. Because the benefits were not region specific, regions with lower wages had higher replacement rates, resulting in higher relative financial incentives for childbearing. I incorporate the 1980 oblastlevel replacement rate into equation (1),

$$
\begin{aligned}
G F R_{o, y}=\alpha & +\gamma_{y}+\delta_{o}+\sum_{t=1975}^{1979} \theta_{t} \times D_{o} \times 1(y=t) \times R_{o} \\
& +\sum_{t=1981}^{1986} \pi_{t} D_{o} 1(y=t) \times R_{o}+X_{o, y}+\varepsilon_{o, y},
\end{aligned}
$$

where $R_{o}$ is a continuous variable measuring the replacement rate. ${ }^{25}$ The coefficient of interest is $\pi_{82}$ and represents the effect of a 1 percentage point increase in the replacement rate on GFR one year after the start of benefits.

\section{Results: Effect of Maternity Benefits Using Annual Data}

Figure 2 displays estimates from equation (1), which represent the covariate-adjusted differences in fertility rates between the early and late beneficiaries in a year compared to the difference in 1980 . The results are weighted by the population of women aged 15 to 44 in 1980 in each oblast. ${ }^{26}$ The standard errors are clustered at the oblast level to allow for an arbitrary correlation structure within an oblast.

\footnotetext{
${ }^{24}$ For late beneficiaries, I estimate, $G F R_{o, y, m}=\alpha+\gamma_{1} y(m)+\beta_{3}$ post $\delta_{o}+\delta_{m}+\varepsilon_{o, y, m}$, where $m$ represents a month, $y(m)$ is a linear time trend, $\delta_{m}$ is a set of month fixed effects, and post is a dummy for the period from November 1981 to October 1982. The coefficient of interest is $\beta_{3}$.

${ }_{25}$ Details for the construction of the replacement rate are in appendix F.

${ }^{26}$ The motivation for weighting is to correct for heteroskedasticity that is related to population size in the oblast by year error terms (Solon, Haider, \& Wooldridge, 2015). I fail to reject that the treatment effect coefficients in weighted and unweighted specifications are the same using a Hausman test.
}

Figure 2.-Short-Run Effect of Maternity Benefits on Fertility Rates

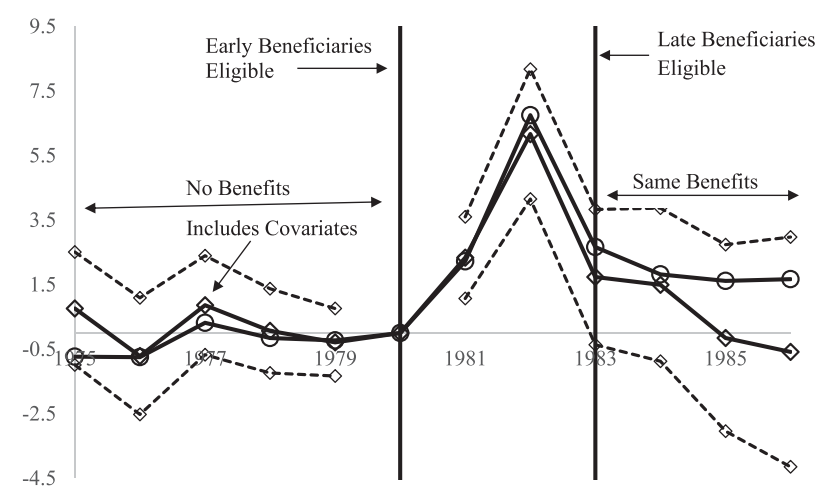

These coefficients represent the difference in GFR (general fertility rates) between the early and late beneficiary regions in each year relative to the difference in 1980. I present $\theta$ and $\pi$ from equation (1) using GFR as a dependent variable. The coefficient on year 1981 presents the effect of the program when maternity benefits were in place in early beneficiaries for two months. The coefficient on year 1982 presents the effect of the program when maternity benefits were in place in early beneficiaries for the full year. For the coefficients shown as circles, the model includes year and oblast fixed effects; for the coefficients shown as diamonds, the model also adds oblast by year covariates. Heteroskedasticity-robust standard errors clustered by oblast construct $95 \%$ point-wise confidence intervals (dashed lines) for the coefficients that include oblast by year covariates. Regressions are weighted by the number of women coefficients that include oblast by year covariates.
who are ages 15 to 44 living in an oblast in 1980.

Sources: Rosstat, 1989 Russian Census, Narodnoe Hozyaystvo yearbooks.

There is no difference in GFR trends in the early and late beneficiaries five years before the program. The point estimates for years 1975 to 1979 are individually indistinguishable from zero and follow a flat trend. These results adjusted for covariates support the findings from the unadjusted series from figure 1 .

The results suggest that the increase in maternity benefits increased fertility rates. Fertility rates rose immediately once early beneficiaries became eligible for benefits in 1981. As expected, the increase in GFR was larger when early beneficiaries were eligible for the entire year (1982) than for part of the year (1981) of benefits. Estimates in table 2 (column 2) imply that GFR jumped by 2.4 and 6.2 births per 1,000 women of childbearing age in 1981 and $1982 .{ }^{27}$ This represents a $3.2 \%$ and $8.2 \%$ increase over a pretreatment mean of 76.0 in early beneficiaries. The difference between the GFR of early and late beneficiaries reverts to the preprogram mean due to an increase in fertility rates in late beneficiaries when they became eligible for the full year of benefits in 1983. This is evidenced by the fact that estimates for 1983 to 1986 are smaller in magnitude than estimates for 1982 and are not statistically different from 0 .

Fertility rates rose more in areas with higher replacement rates. The coefficients in column 3 of table 2 represent the difference in the marginal effect of a 1 percentage point increase in the replacement rate on GFR between early and late beneficiaries in a year relative to this difference in 1980. The pattern of estimates in column 3 supports the finding of an increase in GFR in column 2 and adds that this increase was higher in areas with greater relative financial incentives. In the first year of benefit receipt, GFR increased

\footnotetext{
${ }^{27}$ Estimates are similar in magnitude and statistical significance in a differences-in-differences specification that includes oblast-specific linear time trends and excludes interactions of the early beneficiary dummy with years 1975 to 1979.
} 
Table 2.-Short-Run EfFect of Maternity Benefits on Fertility Rates

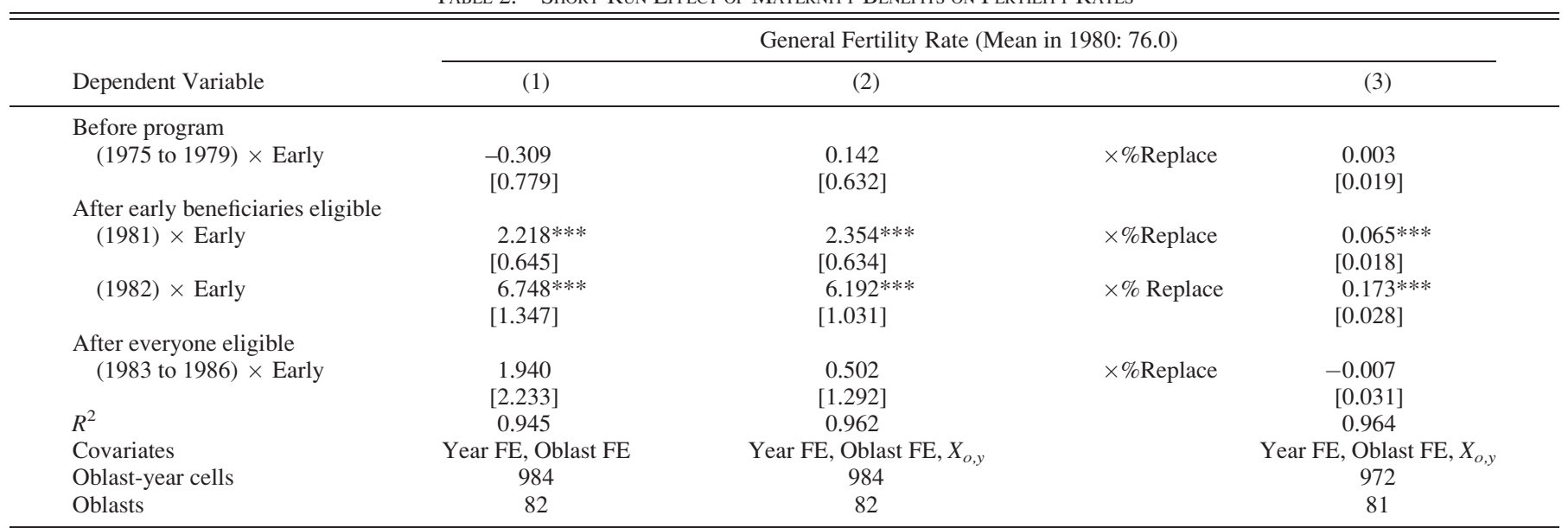

Columns 1 to 2 summarize the coefficients in figure 2 and show interactions of grouped year and early beneficiary dummies using equation (1). Grouped years: before benefits (1975-1979); benefits in place for two months (1981) and benefits in place the whole year (1982) in early beneficiaries; after all regions eligible for benefits (1983-1986). Estimates for 1980 are normalized to 0, because it is omitted. The unit of observation is oblast by year. Column 1 includes grouped year and oblast fixed effects; column 2 adds oblast-level covariates; and column 3 adds annual oblast-level covariates. Column 3 shows interactions of year and early beneficiary dummies with an oblast-level replacement rate of benefits in 1980 using equation (2). Standard errors clustered at the oblast level are in brackets. Regressions are weighted by the number of women ages 15 to 44 living in an oblast in 1980 . Statistically significant at $* * * 0.01, * * 0.05$, and $* 0.10$.

Sources: See the sources for figure 2, and 1994 Russian Statistical Yearbook.

by 0.17 births per woman in response to a 1 percentage point increase in the replacement rate.

A potential threat to internal validity of these estimates could occur if coincidental policies or economic factors affected outcomes. It is unlikely that the estimated effect of maternity benefits is due to other factors because these would need to discontinuously change in 1981 in early beneficiaries and in 1982 in late beneficiaries. In addition to controlling for covariates, I examine the evolution of the growth of industrial product, production of oil, and natural gas in a subset of early beneficiaries and in all of Russia. ${ }^{28}$ In contrast to hypotheses that the increase in fertility rates was due to other factors, all indicators in figure B2 stayed on the same trend around the start of benefits.

\section{Results: Effects of Maternity Benefits Using Monthly Data}

Fertility rates may have gone up six months after women found out about the benefits or even earlier, depending on the prevalence of illegal abortions. In the 1980s, abortion was the most widely used method of fertility regulation in Russia, in part because women had limited access to and education on other types of contraception (Popov, 1991). ${ }^{29}$ Abortions were legal up to the twelfth week of pregnancy, but illegal abortions were also prevalent. The analysis using annual data hides the month-to-month dynamics of fertility rate adjustment. To examine these dynamics, I construct month-level fertility rates using the 2002 Census (see appendix D).

The Census does not include individuals who were born in Russia but emigrated or died before the Census. Consequently, estimates of the number of births using the Census

\footnotetext{
${ }^{28}$ Aggregated data on economic indicators are available only in sixteen of the early beneficiary oblasts.

${ }^{29}$ The adjustment of fertility rates could take longer if women were using contraceptive methods that required medical help to remove or a waiting period until full fecundity.
}

are understated. To correct these estimates, I use the true number of births by oblast and year from the vital statistics data. Specifically, I calculate the proportion of births that are still present in the Census, $p_{o, y}=\left(B_{o, y}^{C}\right) /\left(B_{o, y}^{V}\right)$, where $B_{o, y}^{C}$ is the number of births in oblast, $o$, in year, $y$, recorded in the census, and $B_{o, y}^{V}$ are the number of births in oblast, $o$, in year, $y$, in the vital statistics. Thus, I scale the Census estimates by the proportion of births that are still present in the Census to calculate $B_{o, y, m}^{A}=B_{o, y, m}^{C} / p_{o, y}$. This procedure scales birthrates in each year by a common factor and assumes no differential monthly mortality or mobility. Thus, these estimates preserve the seasonal variation but are rescaled to be comparable to the annual estimates.

I use month-level fertility rates to estimate the following extension of equation (1):

$$
\begin{aligned}
F R_{o, y, m}=\alpha & +\gamma_{y}+\gamma_{m, o}+\delta_{o}+\sum_{t=1979}^{1983} \sum_{k=1}^{12} \pi_{t(k)} \times D_{o} \\
& \times 1(y=t, m=k)+X_{o, y}+\varepsilon_{o, y, m},
\end{aligned}
$$

where $F R_{o, y, m}$ is the fertility rate in oblast $o$, year $y$ and month $m, \gamma$ is a set of month-by-oblast fixed effects that capture seasonality in fertility rates in each oblast, 1() is a dummy for month of observation, while the rest of the variables are the same as in equation (1). The estimates for $\pi$ are normalized 0 in 1978 because this year is omitted. ${ }^{30}$ The coefficient, $\pi_{t(k)}$, is the difference between fertility rates in early and late beneficiaries in year $t$ and month $k$ compared to the difference in 1978.

Estimates of $\pi$ in figure 3 suggest that some of the increase in fertility rates was due to forgone abortions. Fertility rates in early beneficiary oblasts rose about six months after (June 1981) women found out about the benefits

\footnotetext{
${ }^{30} \pi$ contains coefficients, $\pi_{t(k)}$ for years, $t$, from 1979 to 1983 and months, $k$, from 1 to 12 .
} 
Figure 3.-Short-Run Effect of Maternity Benefits on Monthly Fertility Rates

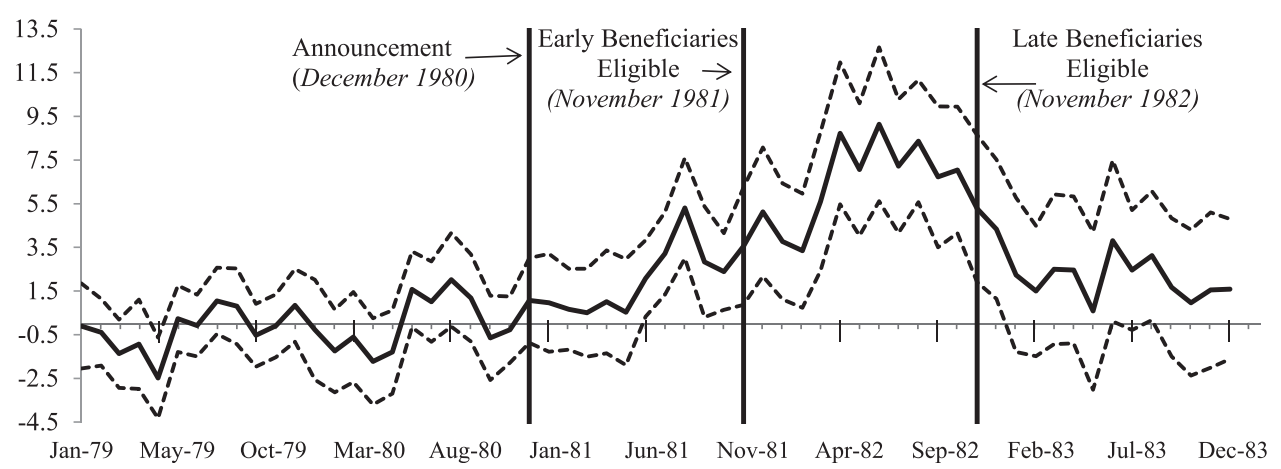

Presented are $\theta$ and $\pi$ from equation (3), showing monthly differences in fertility rates between early and late beneficiaries from January 1979 to December 1983 relative to the difference in 1978 , which is 0 by construction. For weights and standard errors, see notes in figure 2.

Sources: Rosstat, 1989 and 2002 Russian Censuses, and Narodnoe Hozyaystvo yearbooks.

(December 1980), which may be attributable to an increase in forgone abortions. This is before benefits began and may reflect that women could receive some benefits even if they had a child before November 1981, and while women knew benefits would start in 1981, they did not know the month of the start until September 1981. Fertility rates rose even further between November 1981 and October 1982 and stayed higher in every month during that period. Finally, the difference in fertility rates declined once women in late beneficiaries also received the benefits.

\section{Long-Run Effect of Maternity Benefits on Childbearing}

This short-run increase in fertility rates may have been the result of two channels: women gave birth sooner or had children they would not have otherwise had. Given that the goal of maternity benefits was to induce women to have more children, I test whether maternity benefits resulted in an increase in completed childbearing in three ways, estimating the response in fertility rates by parity, the change in the composition of mothers after the start of the program, and the effect of the program on fertility rates over its duration.

\section{A. Effect of Maternity Benefits on Fertility Rates by Parity}

As a first test of whether completed childbearing increased, I examine the response of fertility rates by parity. An increase in first birth fertility rates likely reflected women having desired children sooner because most women in Russia had at least one child. However, an increase in higher-parity fertility rates suggests women had children they would not have otherwise had. I construct first birth and higher-parity fertility rates using the 2010 census data. ${ }^{31}$ I then use equation (1) to test whether the increase in fertility rates was due to first or higher-parity births.

The results suggest that the short-run increase in fertility rates was due to an increase in completed childbearing,

\footnotetext{
${ }^{31}$ Births by parity and oblast are not published in this period. See appendix $\mathrm{D}$, which also describes adjustment for measurement error (similar to section IVD).
}

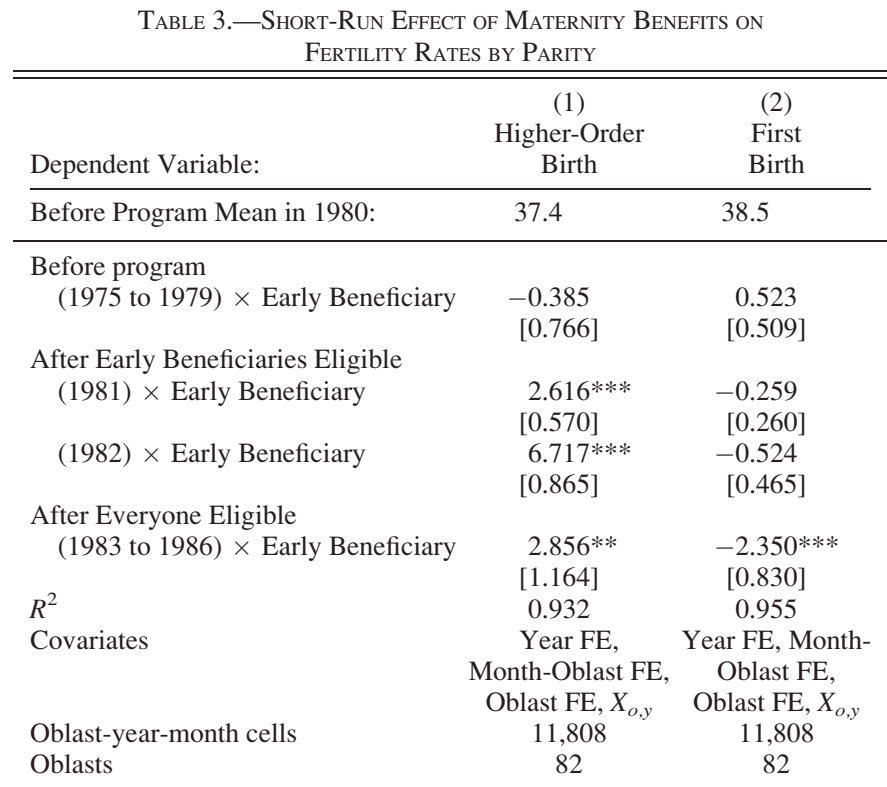

See the notes for table 2 . The dependent variable in column 1 is the fertility rate of second- and higher-order births, and in column 2 it is the fertility rate of first births. The unit of observation is at the year-month-oblast level. Statistically significant at $* * * 0.05$ and $* * 0.10$.

Sources: Rosstat, 1989 and 2010 censuses, Narodnoe Hozyaystvo yearbooks.

because only higher-parity fertility rates increased after the start of benefits. Table 3 shows that the higher-parity fertility rate in early beneficiaries increased by $17.9 \%(6.7$ divided by the preprogram mean of 37.4) in the first year of benefit receipt. The late beneficiaries responded to the program after they became eligible for it; the difference between the fertility rates of early and late beneficiaries shrank starting in 1983. This difference did not shrink to 0 , suggesting a greater increase in fertility rates in the early beneficiaries. Women in early beneficiaries may be more responsive to benefits if they have lower opportunity costs, fewer housing-size constraints, and more resource constraints. ${ }^{32}$ In contrast, the first birth fertility rate in early beneficiaries decreased by an insignificant $1.4 \%(0.5 / 38.5)$.

\footnotetext{
${ }^{32}$ Section VI contains a detailed discussion of heterogeneous responses and mechanisms.
} 
Table 4.-Effect of Maternity Benefits on the Composition of Mothers

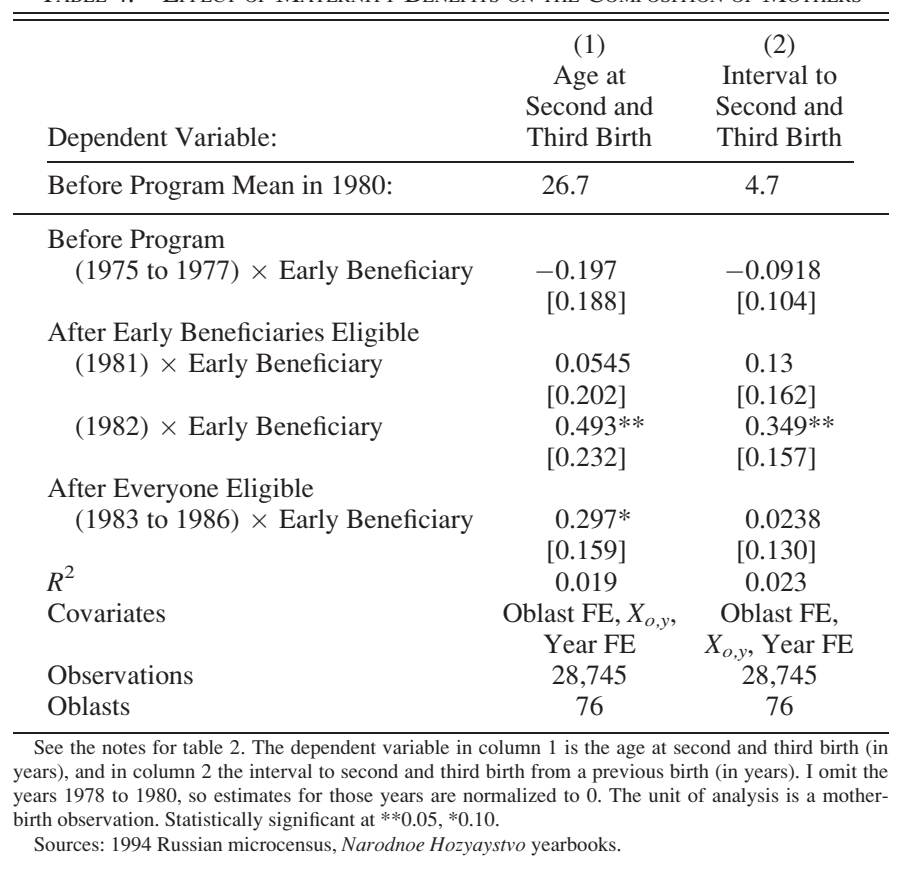

\section{B. Effect of Maternity Benefits on the Composition of Mothers}

As a second test of whether completed childbearing increased, I quantify changes in the composition of mothers who gave birth after the program. The increase in fertility rates was likely due to women having more children-if women who had children after the program were older and had waited longer to have another child. Given the finding that the increase in childbearing is entirely due to the increase in higher-parity births, an increase in completed childbearing would be reflected in an increase in the age of the mother at higher-parity births.

To analyze the composition of women by parity, I use the 1994 Russian microcensus (Goskomstat-MPIDR, 2004) to obtain characteristics of mothers based on when their children were born. No vital statistics data on mothers' characteristics are available. The microcensus is not publicly available, and I use the $0.25 \%$ sample of the population at the Max Planck Institute for Demographic Research. ${ }^{33}$ I estimate equation (1) using the age of mother at the birth of her second and third children and years since last birth as dependent variables. ${ }^{34}$

I find evidence that completed childbearing increased because women who had higher-parity children after the program were older and waited longer to have a child. Table 4 shows that women who had second and third chil-

\footnotetext{
33 Appendix E contains a description of these data. It is impossible to link mothers to children using the 1989, 2002, and 2010 Censuses because they do not contain individual-level data.

${ }^{34}$ The majority of births were parity three and lower. Because I have only a $0.25 \%$ sample of the population, I observe too few fourth and higher-parity births for analysis.
}

dren in the first year of benefit receipt were $5.9(0.493 \times 12$; column 1) months older, and waited $4.2(0.349 \times 12$; column 2) more months to have a child. Thus, the increase in higher-parity births is likely not due to women having these births earlier, but rather due to women having children they would not have otherwise had.

\section{Effect of Maternity Benefits on Long-Run Childbearing}

As a third test of whether completed childbearing increased, I examine the evolution of fertility rates for the ten-year duration of the program. Fertility rates would have risen temporarily and then fallen below previous levels if women only shifted the timing of childbearing. If true, this would have resulted in a 0 net increase in fertility rates over the duration of the program. However, fertility rates would have stayed consistently higher for the duration of the program if women increased their completed childbearing.

To quantify the effects of maternity benefits on childbearing for the duration of the program, I employ an eventstudy framework. This allows me to study the dynamics of the response over a longer time period, which compares fertility rates within an oblast before and after the program compared to fertility rates right before the program (Bailey, Malkova, \& McLaren, in press). I estimate,

$$
\begin{aligned}
G F R_{o, y}= & \alpha+\gamma_{y}+\delta_{o}+\sum_{t=-5}^{-1} \theta_{t} \times 1\left(y-y^{*}=t\right) \\
& +\sum_{t=1}^{11} \pi_{t} \times 1\left(y-y^{*}=t\right)+X_{o, y}+\varepsilon_{o, y}
\end{aligned}
$$

where $y^{*}$ is the year before the start of the program $\left(y^{*}=1980\right.$ for early beneficiaries, while $y^{*}=1981$ for late beneficiaries), and 1() is a dummy that represents years relative to the start of the program. This equation includes year fixed effects that capture nationwide changes in policy and economic conditions, $\gamma_{y}$, oblast fixed effects, $\delta_{o}$, and oblast by year covariates: amount of meat and canned goods produced, and the value of retail trade, $X_{o, y}{ }^{35} \pi_{t}$ measures the effect of maternity benefits on fertility rates $t$ years after the start of the program. ${ }^{36}$ Note that $t=0$ is omitted. Estimates of $\theta$ document if preexisting trends bias estimates of $\pi$, and if "effects" preceded the program.

The event-study analysis has a causal interpretation if the timing of benefit receipt was conditionally random. The government likely chose the early beneficiary oblasts because of their fixed, long-standing characteristics. It has always been the goal to increase population and labor supply in early beneficiaries because of their importance in industrial production. For causality, the early and late beneficiaries may be different; for instance, the early benefici-

\footnotetext{
35 There are fewer covariates than in equation (1) because they are not available for all years.

${ }^{36} \pi_{1}$ should be the smallest, because benefits were in place for only two months in the first year.
} 
Figure 4.-Long-Run Effect of Maternity Benefits on Fertility Rates

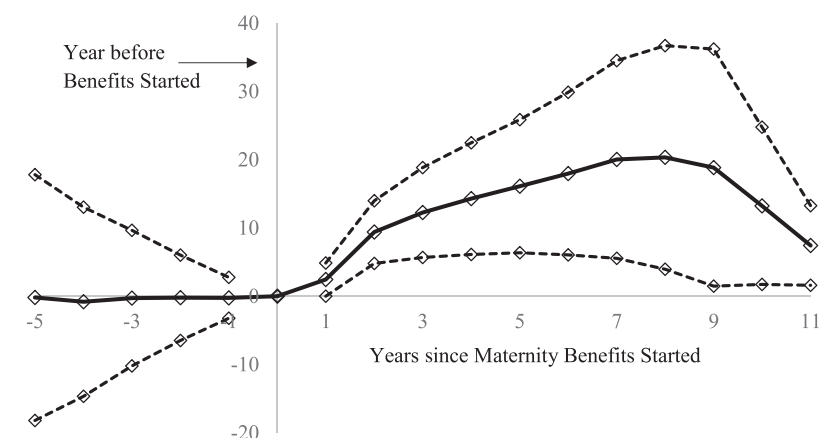

I present $\theta$ and $\pi$ from equation (4) using GFR as a dependent variable. The coefficients are the evolution of GFR conditional on covariates five years before and eleven years after maternity benefits started. Years since maternity benefits equal 0 if birth year is 1980 in early beneficiaries, and 1981 in late beneficiaries. For weights, standard errors, and sources, see figure 2.

aries have a higher fertility rate than the late beneficiaries. This is because the inclusion of oblast fixed effects, $\delta_{o}$, in equation (4) accounts for fixed differences in characteristics across regions, and thus takes care of the government selection of regions based on their fixed characteristics. However, for causality, conditional on covariates, the year an oblast started receiving maternity benefits needs to be random. This assumption would be violated if the government decided the year of maternity benefits start based on previous trends of fertility rates or determinants of childbearing. Thus, I test whether the percent change in fertility rates from 1976 to 1980 predicts the year maternity benefits started. I find that the change in fertility rates has no economically meaningful or significant effect on the year of start. ${ }^{37}$ This evidence suggests that the government did not decide the year of eligibility based on previous trends in fertility rates. Finally, parallel GFR pretrends in early and late beneficiaries (see figure 2) further support the conditional randomness assumption.

I find evidence that completed childbearing increased because the increase in childbearing was sustained for the entire duration of the program. In figure 4, I present eventstudy coefficients $\theta$ and $\pi$ from equation (4) that show changes in fertility rates relative to the year before the benefits started. Estimates to the left of the vertical axis capture the evolution of fertility rates before the program, and estimates to the right of the vertical axis capture the effect of maternity benefits on fertility rates one to ten years after the program started. Table 5 shows that fertility rates were $14.6 \%$ percent higher one to ten years after the program started. There is no evidence that differential preexisting trends bias this analysis or that effects preceded the program because estimates of $\theta$ display a flat trend before the program. Moreover, table 5 shows that higher-parity fertility rates were on average $27.8 \%$ percent higher for the tenyear duration of the program.

\footnotetext{
${ }^{37}$ I perform, Year Start $o=\alpha+\beta \times \%$ Change in $G F R_{o}+\varepsilon_{o}$, where I use the number of women age 15 to 44 as weights. The coefficient $\beta$ is -0.0068 , with a standard error of 0.0109 .
}

Table 5.-Long-Run Effect of Maternity Benefits on Fertility Rates

\begin{tabular}{|c|c|c|}
\hline Dependent Variable: & $\begin{array}{l}\text { (1) } \\
\text { General } \\
\text { Fertility } \\
\text { Rate }\end{array}$ & $\begin{array}{c}(2) \\
\text { Higher- } \\
\text { Order Fertility } \\
\text { Rate }\end{array}$ \\
\hline Before Program Mean: & 70 & 34.6 \\
\hline $\begin{array}{l}\text { Before program event years } \\
\quad(-5 \text { to }-1)\end{array}$ & $\begin{array}{c}-0.061 \\
{[1.018]}\end{array}$ & $\begin{array}{c}1.359 \\
{[0.985]}\end{array}$ \\
\hline $\begin{array}{l}\text { After program event years } \\
\text { (1 to } 3)\end{array}$ & $\begin{array}{l}9.063 * * * \\
{[1.497]}\end{array}$ & $\begin{array}{l}7.004 * * * \\
{[0.999]}\end{array}$ \\
\hline (4 to 6 ) & $\begin{array}{l}10.71 * * * \\
{[2.277]}\end{array}$ & $\begin{array}{l}9.985 * * * \\
{[1.647]}\end{array}$ \\
\hline (7 to 10 ) & $\begin{array}{l}10.84 * * * \\
{[3.463]}\end{array}$ & $\begin{array}{l}11.82 * * * \\
{[2.636]}\end{array}$ \\
\hline$R^{2}$ & 0.914 & 0.887 \\
\hline Covariates & $\begin{array}{c}\text { Year FE, } \\
\text { Oblast FE, } X_{o, y}\end{array}$ & $\begin{array}{c}\text { Year FE, } \\
\text { Month-Oblast FE, } \\
\text { Oblast FE, } X_{o y}\end{array}$ \\
\hline Observations & 1,444 & 17,328 \\
\hline Oblasts & 82 & 82 \\
\hline
\end{tabular}

The coefficients are dummies of grouped years to maternity benefits (event years) from equation (4) where the GFR (column 1) and the higher-order fertility rate (column 2) are dependent variables. The year before benefits started is omitted, so estimates are normalized to 0 for that event year. The unit of observation is oblast by year for column 1 and oblast by year by month for column 2 . For weights, standard errors and sources, see figure 4 . Statistically significant at $* * * 0.01$.

\section{Heterogeneity in Responses to Maternity Benefits}

Next, I examine the effect of maternity benefits by urbanicity and education to shed light on the types of women who increased childbearing in response to maternity benefits. A greater fertility rate increase in more rural and less educated regions could be due to lower opportunity costs, fewer housing size constraints, or more resource constraints. First, both rural and less educated women had lower opportunity costs because of lower wages, making the benefit a higher fraction of their salary. ${ }^{38}$ Second, rural women had fewer housing-size constraints due to larger housing size relative to urban women, allowing them more housing space to accommodate another child. Third, rural and less educated women were more resource constrained due to lower wages, making the financial aspect of maternity benefits more valuable to them.

To quantify the effect of maternity benefits by urbanicity and education, I follow Finkelstein (2007), using the characteristics of oblasts from the 1979 Russian census, to estimate,

$$
\begin{aligned}
G F R_{o, y}=\alpha & +\gamma_{y}+\sum_{t=-6}^{-1} \theta_{t} \times Z_{o} \times 1\left(y-y^{*}=t\right) \\
& +\sum_{t=1}^{10} \pi_{t} \times Z_{o} * 1\left(y-y^{*}=t\right)+\delta_{o} \\
& +X_{o, y}+\varepsilon_{o, y},
\end{aligned}
$$

where $Z_{o}$ represents continuous variables at the oblast level, measured in 1979, in separate regressions: share of women

\footnotetext{
${ }^{38}$ Rural women mostly worked as low-paid manual laborers and had work flexibility due to the seasonal nature of their work (Bridger, 1987).
} 
Figure 5.-Heterogeneous Responses of Fertility Rates to Maternity BENEFITS ACROSS REgIONS

A. Share of Women Age 15 to 44 Living in Rural Areas

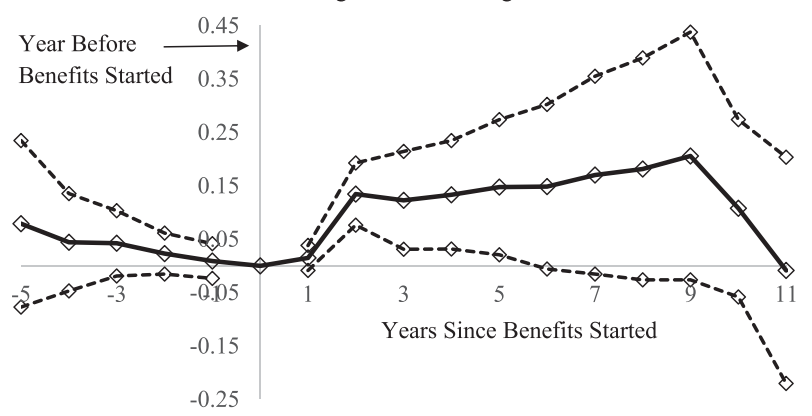

B. Share of Individuals Older than 10 with Less than High School Education

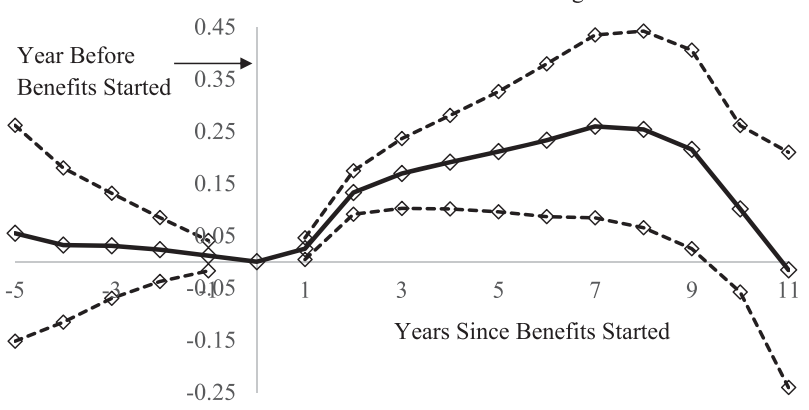

I present $\theta$ and $\pi$ from equation (5) using GFR as a dependent variable, representing interactions of event-year dummies with an oblast-level characteristic measured in 1979. (A) Share of women age 15 to 44 in rural areas and (B) share of individuals with less than high school education. For weights and standard errors see figure 2 .

Sources: Figure 2 sources and 1979 Census.
dard errors see figure

age 15 to 44 living in a rural area and share of individuals age 10 and older who have not completed high school. All other covariates remain the same as in equation (4), except now the event-year dummies, $1\left(y-y^{*}=t\right)$, are interacted with $Z_{o}$.

This strategy tests for a break in any preexisting differences in the level or trend of fertility rates across regions at the start of the program that is correlated with $Z_{o}$. The identifying assumption is that without benefits, the differences in fertility rates before the start of the program would have continued on the same trend. This strategy does not assume that areas that differ in their composition of residents had the same level or growth of fertility rates before the program.

Maternity benefits are associated with a greater increase in fertility rates among more rural and less educated areas. Figure 5 plots estimates of $\theta$ and $\pi$ from equation (5) that correspond to interactions of the event-year dummies with variables measuring a region's rural (panel $\mathrm{A}$ ) and education status (panel B) in separate regressions. Table B1 summarizes these estimates. The coefficients are individually statistically indistinguishable from 0 in the years leading up to the program. This indicates that before the program, fertility rates evolved similarly in areas with different shares of urban women and educated individuals. However, after the program, the coefficients, $\pi$, jump discontinuously in both panels. This indicates a larger increase in fertility rates in more rural compared to more urban areas and a larger increase in fertility rates in less educated compared to more educated areas. The GFR in more rural and less educated areas continued increasing by more for the first eight years after the start of the program. However, the difference across regions disappeared ten years after the start of the program, which is consistent with benefits losing their value due to inflation and the end of the program.

The greater increase in fertility rates in more rural and less educated regions provides suggestive evidence that the magnitudes of effects of maternity benefits may depend on opportunity costs, housing size constraints, and resource constraints. However, this study is unable to distinguish between the importance of these channels due to the lack of individual-level data.

\section{Adult Outcomes of Children Born before and after Maternity Benefits}

Given the increase in childbearing and the change in composition of mothers, I examine the adult outcomes of children born after maternity benefits. For this purpose, I use 2010 Russian Census data, which include all individuals living in Russia in 2010. These data are tabulated based on the individual's oblast and year of birth. I focus on outcomes such as percent completed college, employed, receiving public assistance, married, teen mothers, and the average number of children.

I use a differences-in-differences framework to estimate the effect of maternity benefits on adult outcomes of children born one year after the program in the following equation,

$$
\begin{aligned}
Y_{o, y}= & \alpha+\pi_{81} \times D_{o} \times 1(y=81)+\pi_{82} \times D_{o} \\
& \times 1(y=82)+\gamma_{y}+\delta_{o}+\delta_{o} \times y+\varepsilon_{o, y},
\end{aligned}
$$

where $Y_{o, y}$ is an outcome in 2010 for children born in oblast, $o$, and in year, $y$ (1976 to 1982); $D_{o}$ is a dummy for being born in an early beneficiary oblast; $1(y=81)$ is a dummy for birth year 1981, and $1(y=82)$ is a dummy for birth year $1982, \delta_{o}$ are oblast fixed effects, $\gamma_{y}$ are birth year fixed effects; $\delta_{o} \times y$ are linear time trends for every oblast, which control for any differential linear trends in outcomes within an oblast. The coefficients $\pi_{81}$ and $\pi_{82}$ capture the effect of maternity benefits on outcomes of children born in 1981 and 1982.

The estimates of the effect on outcomes reflect the combination of the direct and the indirect effect of maternity benefits. The direct effect could be due to the parental time or household income channels. First, adult outcomes may be affected if mothers take longer leaves. Second, adult outcomes may be affected if paid leave raises household income or lowers it if mothers take a lot more leave. ${ }^{39}$ The indirect effect could be due to the parental composition and cohort- and household-size channels. First, the average

\footnotetext{
${ }^{39}$ Expansions of maternity leave have both positive and no effects on economic and health outcomes in childhood and adulthood (Baker \& Milligan, 2010; Carneiro, Loken, \& Salvanes, 2015; Dahl et al., 2016; Dustmann \& Schönberg, 2012; Liu \& Skans, 2010; Rossin, 2011). Early life conditions may affect outcomes later in life (Van den Berg, Lindeboom, \& Portrait, 2006).
} 
Table 6.-Effect of Maternity Benefits on Adult Educational, Economic, and Family Structure Outcomes

\begin{tabular}{|c|c|c|c|c|c|c|c|c|}
\hline $\begin{array}{l}\text { Dependent } \\
\text { Variable: }\end{array}$ & $\begin{array}{c}\text { (1) } \\
\% \text { at Least } \\
\text { Some College }\end{array}$ & $\begin{array}{c}(2) \\
\text { Education } \\
\text { Index }\end{array}$ & $\begin{array}{c}(3) \\
\% \text { Men } \\
\text { Employed }\end{array}$ & $\begin{array}{c}(4) \\
\% \text { Women } \\
\text { Employed }\end{array}$ & $\begin{array}{c}5) \\
\% \text { Public } \\
\text { Assistance }\end{array}$ & $\begin{array}{c}(6) \\
\% \\
\text { Married }\end{array}$ & $\begin{array}{c}(7) \\
\% \text { Teen } \\
\text { Mothers }\end{array}$ & $\begin{array}{c}(8) \\
\text { Number of } \\
\text { Children }\end{array}$ \\
\hline Mean If Born in 1979 & 33.1 & 5.3 & 85.8 & 75.9 & 6.6 & 54.3 & 19.0 & 1.3 \\
\hline \multicolumn{9}{|c|}{ After early beneficiaries eligible } \\
\hline$(1981) \times$ Early & $\begin{array}{l}-0.165 \\
{[0.184]}\end{array}$ & $\begin{array}{c}0.006 \\
{[0.010]}\end{array}$ & $\begin{array}{c}0.305 \\
{[0.192]}\end{array}$ & $\begin{array}{c}0.249 \\
{[0.244]}\end{array}$ & $\begin{array}{c}-0.097 \\
{[0.068]}\end{array}$ & $\begin{array}{c}0.296 \\
{[0.322]}\end{array}$ & $\begin{array}{c}0.084 \\
{[0.203]}\end{array}$ & $\begin{array}{c}-0.001 \\
{[0.005]}\end{array}$ \\
\hline$(1982) \times$ Early & $\begin{array}{l}-0.240 \\
{[0.214]}\end{array}$ & $\begin{array}{c}0.000 \\
{[0.010]}\end{array}$ & $\begin{array}{c}0.282 \\
{[0.227]}\end{array}$ & $\begin{array}{c}0.384 \\
{[0.256]}\end{array}$ & $\begin{array}{c}-0.112 \\
{[0.102]}\end{array}$ & $\begin{array}{c}0.326 \\
{[0.358]}\end{array}$ & $\begin{array}{c}0.362 \\
{[0.342]}\end{array}$ & $\begin{array}{c}-0.001 \\
{[0.006]}\end{array}$ \\
\hline $\mathrm{R}^{2}$ & 0.998 & 0.999 & 0.996 & 0.998 & 0.995 & 0.995 & 0.990 & 0.998 \\
\hline Oblast-year cells & 574 & 574 & 574 & 574 & 574 & 574 & 574 & 574 \\
\hline Oblasts & 82 & 82 & 82 & 82 & 82 & 82 & 82 & 82 \\
\hline
\end{tabular}

The coefficients are the difference in outcomes between the children born in early compared to late beneficiaries in 1981 and 1982 relative to the difference from 1976 to 1980 . I present $\pi_{81}$ and $\pi_{82}$ from equation (6) using adult outcomes as dependent variables. The unit of observation is birth oblast by birth year, the analysis includes outcomes of children born between 1976 and 1982 . All columns include birth year, and oblast of birth fixed effects, and linear time trends interacted with birth oblast fixed effects. Regressions are weighted by the number of children born in each oblast in 1979. Standard errors clustered at the oblast-level are in brackets.

Source: 2010 Russian Census.

child's adult outcomes may change due to the change in the composition of mothers. The greater fertility increase in less educated and more rural regions suggests that the increase in births was due to more disadvantaged mothers. This could lead the average child to also be more disadvantaged. ${ }^{40}$ Second, the average child's adult outcomes may change due to being part of a larger cohort or due to having more siblings.

I do not find evidence that maternity benefits had an effect on children's educational, economic, and family structure outcomes between the ages of 25 and 32. Table 6 shows that the effects on college completion and the linear education index are negative in sign but small in magnitude and not statistically significant. ${ }^{41}$ Children born in the first year of benefit receipt are 0.24 percentage points less likely to complete college, which represents a $0.73 \%$ decline.

\section{Discussion and Conclusion}

Low fertility rates are an important concern for many OECD countries that have implemented various familyfriendly policies. I find an immediate response in fertility rates after the introduction of paid parental leave and cash transfers in Russia. Moreover, I find that the effects on fertility rates persist in the long run. These results indicate that maternity benefits affected both the timing and the number of children women had.

These results imply that childbearing is elastic with respect to the cost of a child. A back-of-the-envelope calculation quantifies this price elasticity. I use estimates from Russian demographers to calculate the cost of a child as the sum of the costs over the first 18 years of a child's life (Valentei, 1987). In Russia, maternity benefits decreased

\footnotetext{
${ }^{40}$ Children of disadvantaged mothers may also be disadvantaged: family characteristics may be important for future earnings, and wellbeing (Almond \& Currie, 2011).

${ }^{41}$ I find no evidence that these results are due to measurement error from mortality and emigration. I construct the GFR with 2010 Census data and use it as a dependent variable in equation (6). I find an $8.7 \%$ $\left(\pi_{82}\right)$ increase in GFR, which is similar to the $8.2 \%$ increase in GFR (table 2) using data without measurement error.
}

the cost of a child by $2.2 \%$ (see appendix G). According to estimates in table 2, this is associated with an $8.2 \%$ increase in fertility rates (6.2/76) during the year after the start of the program, which means that the short-run price elasticity of childbearing equals $-3.7(8.2 / 2.2)$.

How does the effect of maternity benefits on childbearing in Russia compare to effects of family benefits in other countries? To address this question, I compare the estimates of short-run elasticities from other studies, which range from -4.4 to 0.54 (see figure B3). The estimate of the elasticity in this study is in this range of other countries. ${ }^{42} \mathrm{I}$ construct corresponding confidence intervals for these elasticities using a parametric bootstrap method. The confidence intervals of all but the study on Israel overlap.

This study has three caveats. First, the results of this study apply in a specific context. In Soviet Russia, women had high labor force participation rates, earned substantially less than men, the age-wage profile was flatter than in other countries, and child care was widespread and heavily subsidized. The long-term effect of maternity benefits may differ in countries with different female labor market characteristics and the availability of other social programs.

Second, this study cannot disentangle the precise mechanisms contributing to the increase in childbearing. More rural and less educated regions experienced greater increases in childbearing, which is consistent with several potential mechanisms: opportunity costs, housing-size constraints, and resource constraints. However, the lack of individual-level data limits the identification of the most important mechanism. Further work should explore both the characteristics of women who change their behavior and the interaction of their response with the characteristics of the context. Such an analysis is valuable for countries that want to design effective maternity benefit programs.

Third, the lack of an effect of maternity benefits on outcomes in adulthood may not translate into a lack of a direct

\footnotetext{
${ }^{42}$ Table B2 shows that key demographic and economic characteristics in Russia in 1980 are comparable to those in Austria, Spain, Italy, the United States, and Sweden over 2010 to 2013.
} 
effect in adulthood or in childhood. If a mother's characteristics affect the characteristics of her child in adulthood, then this finding may indicate that maternity benefits have a direct effect of making adult outcomes more advantaged. For instance, no effect on educational attainment in adulthood may reflect that the direct benefit of maternity benefits (increase in educational attainment) counteracted that children born as a result of maternity benefits had less educated mothers. Moreover, the transition to a market economy in the 1990s may have been a big enough shock to mask direct effects that were present in childhood. I am unable to investigate this, because data on childhood outcomes in the 1980s are not available.

To conclude, this study is the first to find a positive longterm effect of maternity benefits on childbearing. My estimates imply that the program induced about 5 million births during its ten-year duration at a cost of roughly 2,830 rubles per birth induced (see appendix G). At the time, the cost represented 1.4 times the average national yearly salary in 1980. This study conveys a hopeful message that maternity benefits can succeed in their goal of leading women to have more children in the long term.

\section{REFERENCES}

Almond, Douglas, and Janet Currie, "Human Capital Development before Age Five" (pp. 1315-1468), in O. Ashenfelter and D. Card, eds. Handbook of Labor Economics, vol. 4b (Maryland Heights, MO: Elsevier 2011).

Bailey, Martha, Olga Malkova, and Zoë McLaren, "Does Access to Family Planning Increase Children's Opportunities? Evidence from the War on Poverty and the Early Years of Title X," Journal of Human Resources (in press).

Baker, Michael and Kevin Milligan, "Evidence from Maternity Leave Expansions of the Impact of Maternal Care on Early Child Development," Journal of Human Resources 45 (2010), 1-32.

Becker, Gary S., "A Theory of the Allocation of Time," Economic Journal 75 (1965), 493-517.

Becker, Gary S., and H. G. Lewis, "On the Interaction between Quantity and Quality of Children.” Journal of Political Economy 81 (1973), S279-288.

Black, Dan A., Natalia Kolesnikova, Seth G. Sanders, and Lowell J. Taylor, “Are Children 'Normal'?" this REVIEw 95 (2013), 21-33.

Bloom, David E., David Canning, Günther Fink, and Jocelyn E. Finlay, "The Cost of Low Fertility in Europe," European Journal of Population 26 (2010), 141-158.

Brainerd, Elizabeth, "Winners and Losers in Russia's Economic Transition," American Economic Review 88 (1998), 1094-1116.

"Women in Transition: Changes in Gender Wage Differentials in Eastern Europe and the Former Soviet Union," Industrial and Labor Relations Review 54 (2000), 138-162.

Bridger, Susan, Women in the Soviet Countryside: Women's Roles in Rural Development in the Soviet Union (Cambridge: Cambridge University Press, 1987).

Carneiro, Pedro, Katrine Loken, and Kjell Salvanes, "A Flying Start? Maternity Leave Benefits and Long Run Outcomes of Children," Journal of Political Economy 123 (2015), 365-412.

Central Intelligence Agency, The World Factbook (Washington, DC: CIA, 2013)

Chinn, Jeff, Manipulating Soviet Population Resources (London: Macmillan, 1977).

Cohen, Alma, Rajeev Dehejia, and Dmitri Romanov, "Financial Incentives and Fertility," this REVIEw 95 (2013), 1-20.

Dahl, Gordon, Katrine Løken, Magne Mogstad, and Kari Vea Salvanes, "What Is the Case for Paid Maternity Leave?" this REVIEW 98 (2016), 655-670.
Demeny, Paul, "Pronatalist Policies in Low-Fertility Countries: Patterns, Performance, and Prospects," Population and Development Review 12 (1986), 225-258.

Desfosses, Helen, "Pro-Natalism in Soviet Law and Propaganda" (pp. 95-123), in Helen Desfosses, ed., Soviet Population Policy: Conflicts and Constraints (New York: Pergamon Press, 1981).

DiMaio, Alfred, "Contemporary Soviet Population Problems" (pp. 1643), in Helen Desfosses, ed., Soviet Population Policy: Conflicts and Constraints (New York: Pergamon Press, 1981).

Dustmann, Christian, and Uta Schönberg, "Expansions in Maternity Leave Coverage and Children's Long-Term Outcomes," American Economic Journal: Applied Economics 4 (2012), 190-224.

Finkelstein, Amy, "The Aggregate Effects of Health Insurance: Evidence from the Introduction of Medicare," Quarterly Journal of Economics 122 (2007), 1-37.

Galor, Oded, and David N. Weil, "From Malthusian Stagnation to Modern Growth," American Economic Review 89 (1999), 150-154.

Gauthier, Anne H., and Jan Hatzius, "Family Benefits and Fertility: An Econometric Analysis," Population Studies 51 (1997), 295-306.

Gonzalez, Libertad, "The Effect of a Universal Child Benefit on Conceptions, Abortions, and Early Maternal Labor Supply," American Economic Journal: Economic Policy 5 (2013), 160-188.

Goskomstat-MPIDR, 1994 Russia Microcensus Extracts at the Max Planck Institute for Demographic Research (2004).

Gregory, Paul H., and Janet E. Kohlhase, "The Earnings of Soviet Workers: Evidence from the Soviet Interview Project," this REVIEW 70 (1988), 23-35.

Guger, A., "Direkte und indirekte Kinderkosten in Österreich. Ein Überblick, WIFO Monatsberichte 9 (2003), 693-698.

Hoynes, Hilary W., "Work, Welfare, and Family Structure," in Alan B. Auerbach, ed., Fiscal Policy: Lessons from Economic Research (Cambridge, MA: MIT Press, 1997).

Jacobson, Louis S., Robert J. LaLonde, and Daniel G. Sullivan, "Earnings Losses of Displaced Workers," American Economic Review 83 (1993), 685-709.

Lalive, Rafael, and Josef Zweimüller, "How Does Parental Leave Affect Fertility and Return to Work? Evidence from Two Natural Experiments," Quarterly Journal of Economics 124 (2009), 1363-1402.

Lindo, Jason, "Are Children Really Inferior Goods? Evidence from Displacement Driven Income Shocks," Journal of Human Resources 45 (2010), 301-327.

Litvinova, G. I., "The Effect of Government and Law on Demographic Processes," Soviet State and Law 1 (1978), 132-136.

Liu, Qian, and Oskar Skans, "The Duration of Paid Parental Leave and Children's Scholastic Performance," B.E. Journal of Economic Analysis and Policy 10 (2010), 1-35.

Lovenheim, Michael F., and Kevin J. Mumford, "Do Family Wealth Shocks Affect Fertility Choices? Evidence from the Housing Market," this REVIEW 95 (2013), 464-475.

Milligan, Kevin, "Subsidizing the Stork: New Evidence on Tax Incentives and Fertility," this REVIEW 87 (2005), 539-555.

Moffitt, Robert A., "The Effect of Welfare on Marriage and Fertility," in Robert A. Moffitt, ed., Welfare, the Family, and Reproductive Behavior (Washington, DC: National Academy Press, 1998).

Perevedentsev, Viktor I., "Population Distribution and Migration," Zhurnalist no. 2 (1974).

Popov, Andrej A., "Family Planning and Induced Abortion in the USSR: Basic Health and Demographic Characteristics," Studies in Family Planning 22 (1991), 368-377.

Rossin, Maya, "The Effects of Maternity Leave on Children's Birth and Infant Health Outcomes in the United States," Journal of Health Economics 30 (2011), 221-239.

Solon, Gary, Steven J. Haider, and Jeffrey Wooldridge, "What Are We Weighting For?" Journal of Human Resources 50 (2015), 301-316.

United Nations, "World Population Policies," Department of Economic and Social Affairs, Population Division, New York (2013).

Valentei, Dmitrii, The Urban and Rural Family (Moscow: Mysl', 1987).

Van den Berg, Gerard J., Maarten Lindeboom, and France Portrait, "Economic Conditions Early in Life and Individual Mortality," American Economic Review 96 (2006), 290-302.

Weber, Cynthia, and Ann Goodman, "The Demographic Policy Debate in the USSR," Population and Development Review 7 (1981), 279-295.

Willis, Robert J., "A New Approach to the Economic Theory of Fertility Behavior," Journal of Political Economy 81 (1973), S14-S64. 